INDO GLOBAL JOURNAL OF

PHARMACEUTICAL SCIENCES

ISSN 2249- 1023

\title{
Transdermal Patches for Treatment of Diabetic Neuropathy
}

\author{
Rashi Rajput, Deepak Prajapat, Neeti Mittal, Ketan Saraf, Manisha Singh * \\ Department of Biotechnology, Jaypee Institute of Information Technology, Noida-201307, U.P., India
}

Address for Correspondence: Manisha Singh; manishasingh1295@gmail.com

\begin{abstract}
Transdermal drug delivery systems are gaining momentum as the preferred choice of drug administration owing to the several advantages they offer, cardinal being bypass of hepatic metabolism of the drug, which in case of oral administration is a major drawback, declining the bioavailability of the drug consumed. There are innumerable Transdermal drug delivery systems; Transdermal patches being one of them and composed of a backing membrane, a drug reservoir and a protective liner. Gabapentin is an anticonvulsant neurotransmitter which has its role in inhibition of pain transmission and modulation. It inhibits the neuronal calcium influx in central nervous system and thus comes in category of calcium-channel modulator. Several studies have proved the use of gabapentin for the treatment of diabetic neuropathic pain which is available in oral, suspension and intra venous drug delivery systems in the market. In present study, the transdermal patches of gabapentin were prepared by solvent evaporation method using different polymer PVP, HPMC, Ecopol L100 and Ecopol S100 in different ratios. PVA (Poly Vinyl Alcohol) backing membrane was also prepared for the same along with PEG 400 as plasticizer and DMSO as permeation enhancer. Further, Physico-chemical characterization of optimised transdermal patches were done like smoothness, flexibility, folding endurance, flatness, thickness, moisture content, and moisture absorption. The in vitro permeation studies using dialysis membrane on Franz diffusion cell revealed the sustained and constant release of drug from the patch. (c) 2014 iGlobal Research and Publishing Foundation. All rights reserved.
\end{abstract}

Conference Proceedings: International Conference on Life Sciences, Informatics, Food and Environment; August 29- 30, 2014

Indo Global Journal of Pharmaceutical Sciences( ISSN 22491023 ; CODEN-I IGJPAI; NLM ID: 101610675) indexed and abstracted in EMBASE(Elsevier), SCIRUS(Elsevier),CABI, CAB Abstracts, Chemical Abstract Services(CAS), American Chemical Society(ACS), Index Copernicus, EBSCO, DOAJ, Google Scholar and many more. For further details, visit 